\title{
Architecture_MPS
}

\section{Rendering the Social in the Architectural Scene: Digital Representation and Social Inclusion on Architectural Design, Thinking, and Education}

Brian McGrath ${ }^{1}$, Cheng-Leun Hsueh ${ }^{1}$, Paul Chu Hoi Shan ${ }^{2}$

How to cite: McGrath, B, Hsueh, CH, Shan, P. C. H. 'Rendering the Social in the Architectural Scene: Digital Representation and Social Inclusion on Architectural Design, Thinking, and Education.' Architecture_MPS, 2016, 8(1): 4. DOI: https://doi.org/10.14324/111.444.amps.2016v8i4.001.

Published: 01 February 2016

\section{Peer Review:}

This article has been peer reviewed through the journal's standard double blind peer-review, where both the reviewers and authors are anonymised during review.

\section{Copyright:}

(c) 2016, The Author(s). This is an Open Access article distributed under the terms of the Creative Commons Attribution License (CC-BY) 4.0 https://creativecommons.org/licenses/by/4.0/, which permits unrestricted use, distribution and reproduction in any medium, provided the original author and source are credited • DOI: https://doi.org/10.14324/111.444.amps.2016v8i4.001.

\section{Open Access:}

Architecture_MPS is a peer-reviewed open access journal. 


\title{
Title: Rendering the Social in the
} Architectural Scene: Digital Representation
and Social Inclusion on Architectural Design,
Thinking, and Education

\section{Author: Brian McGrath, Cheng-Leun Hsueh, Paul Chu Hoi Shan}

\section{Architecture_media_politics_society. voll.8, no.4.}

February 2016

Affiliation: Parsons School of Design, National Cheng Kung University,

Chu Hai College of Higher Education

\begin{abstract}
The digital production of hyper-rendered scenes has come to dominate architectural practice. Jean Baudrillard's warning that simulation will replace the real is now obvious and ubiquitous in our wirelessly networked mediated lives. CAD monkeys, rendering farms, and out-sourcers form the cabal behind the global production of seductive computer generated imagery detached from real people and places. This paper builds on the premise that physical places, designed and marketed through digital imagery, set the stage for the "social scenes" of tourism, leisure and consumption, and that privatized public spaces become "images" in themselves. Providing a setting for ways of people seeing, and being seen by others, these images encourage us to mimic the poses and gestures of architectural renderings. Standing against our growing obsession with rendered architectural scenes suggests that, as digital modes of creation and representation increasingly become objectives in and of themselves, architectural practice is prone to blindness in the face of social developments which exist independently of architecture's digital turn. The paper highlights the possible integration of the social and the technological through documenting a series of design, professional, and pedagogical projects which have, during the thirty-year period of architecture's 'digital turn', increasingly incorporated 'the digital', but which have persistently continued to foreground the social.
\end{abstract}




\title{
Title: Rendering the Social in the Architectural Scene: Digital Representation and Social Inclusion on Architectural Design, Thinking, and Education
}

\author{
Author: Brian McGrath, Cheng-Leun Hsueh, \\ Paul Chu Hoi Shan
}

Architecture_media_politics_society. vol. 8, no. 4 .

February 2016

\section{Introduction}

The digital production of hyper-rendered scenes has come to dominate architectural practice. Jean Baudrillard's warning that simulation will replace the real is now obvious and ubiquitous in our wirelessly networked mediated lives. ${ }^{1}$ CAD monkeys, rendering farms and out-sourcers form the cabal behind the global production of seductive computer generated imagery detached from real people and places. This paper builds on the premise that the introduction of digitally enhanced architectural scenes to a mass public has been commonplace for some time - its most notable manifestation being the public review process around the rebuilding of New York's World Trade Center. Functioning as a succinct example of the dangers embedded in our seduction by hyper-rendered scenes, the World Trade Center project saw a potentially important public debate about the future of the city hijacked by the dizzying spectacular display of animated architectural scenery. ${ }^{2}$

In stark contrast to this visual focus, recent social theory recognizes physical "urban scenes" as "settings structuring shared cultural consumption"3 and suggests that a focus on glossy hyper-real simulation in the presentation of architecture has amplified the commodification of space in contemporary society. Physical places, designed and marketed through digital imagery, set the stage for the "social scenes" of tourism, leisure and consumption in which privatized public spaces become "images" in themselves. Using the notion of "scene" and "scenery" to develop its argument, this paper suggests these images encourage us to mimic the poses and gestures of architectural renderings. Positioning itself against our growing obsession with rendered 


\section{Amps}

architectural scenes and the commodified spaces they produce, it suggests that focusing on digital advances in architectural representation limits our understanding of the social impact of architectural "scene making".

This paper then, argues that as digital modes of creation and representation increasingly become objectives in and of themselves, architectural practice becomes ever more prone to blindness in the face of social developments which exist independently of architecture's digital turn. Proposing that some of these new social movements have actually aligned themselves with digital innovations it suggests there is no reason why the potential of digital rendering and design should distance us from the social role and consequences of architecture. In short, it suggests that new modes of digital production should not retreat from the social content of architecture and it seeks to highlight the possible integration of the social and technological. It does so by initially offering a historical precedent through the work of Piranesi, and then by a series of short summaries of various design, professional, and pedagogical projects. Developed during the thirty-year period of architecture's "digital turn," these projects are examples of how increasingly to incorporate "the digital," but continue to foreground the social. It thus underlines that as the production and representation of architecture evolves technologically it can, and should, be ever more aligned with its social role and implications, whether understood in a pedagogical or professional context. ${ }^{4}$

\section{Defining the Scene}

The common professional presentation of an architectural "scene" tends to be limited to this visual understanding - the presentation of a picture of an imagined place to the eye - normally for commercial ends. In this sense, our use and consideration of architecture's new potential in visually creating and presenting scenes is clearly limited. It is, however, a potentially powerful - albeit underutilized - tool in engaging with and presenting various social agendas which, inevitably, develop their own particular social and spatial patterns. An indication of the possibilities latent in this appear if we consider momentarily the possible readings of the word "scene" more broadly.

The Oxford English Dictionary has multiple definitions of the word "scene." The word's origin comes, in its theatrical sense, from the classical Greek term for the marked subdivision of a play "in which time is continuous and setting fixed." In addition to this distinct temporal definition of the scene, there is the distinct physical form of representation through "pieces of scenery used in a play to depict a setting," in other words, the construction of an artifice to bring the audience to an imagined setting. The word scene also refers to the "action or presentation of a dramatic piece on stage; a play in performance," and finally to the "place in which the action of (part of) a play is supposed to occur."

While the origins of the word scene lie in the theatrical arts, it has increasingly come to take on expanded meanings where "all the world is a stage." 


\section{Amps}

The "scene" in the contemporary sense means any place where "action is carried on, business is being done, or events are happening." In its theatrical context, it means "an action, episode, situation, etc. which forms a subject of narration, or description/occurring in real life." Sometimes life can be as dramatic as art of course. We also use the word scene to refer to a "display of anger or other strong feeling, especially in public; a row, a disturbance." However, in addition referring to actual place and action, scene is also defined as "a view or picture presented to the eye (or to the mind) - whether of a place, a series of actions or events, or a collection of objects, etc." 5 In combining these varied definitions of the notion of "scene" as representing time, constructed artifice, action, and imagined place, this paper proposes a radical expansion of the typically reductive notion of visual "scenes" as employed in contemporary architecture.

\section{A Historical Scene: A Precedent for Technological Advances and Social Critique}

Architectural representation is a magical art. On the drafting board we flatten three-dimensional structures in scaled and measured two-dimensional projections. Orthographic drawings are horizontal and vertical dissection cuts through imagined building matter, which must be read in correspondence to each other in order to imagine the three-dimensional spatial reality of architecture. Axonometry is a form of parallel projection that warps the brain, as a drawn line could be perceived to be projecting forward or back in space. This optical flipping turns a volume inside out as one looks at a page. Perspective is the conjuring of a picture like scene from two orthographic drawings by means of a complex system of establishing a picture plane, station points, horizon line, and vanishing points. However, laboriously produced, the perspective representation is limited to the visual experience of a monocular viewer at a slice of time. Despite our current and previous obsession with or nostalgia for different forms of architectural representation, Robin Evans has critically positioned it as a transitive medium. This shifts attention from the drawing or image to something more intangible located between orthographic projection, perspective, and the observer's perception and imagination. ${ }^{6}$

This understanding is in clear counter distinction to the delirium that can be induced by powerful architectural representation - whether current or historical. Giovanni Battista Piranesi's play with cinema-like montage in the construction of theatrical perspectival scenes of eighteenth-century Rome came, according to Marguerite Yourcenar, from a "dark brain."7 Indeed, it is reported in his biography that Piranesi entered into malarial fever as he sketched the ruins of Rome in the field. ${ }^{8}$ The etching plate became for him a medium in which to register his feverish experience of the ruins of ancient Rome within scenes of the baroque social life of the papal city. These images were not only fantastical but involved a significant technological breakthrough - his mastery of the etched print. 


\section{Amps}

However, what concerns us here is that Piranesi's Views of Rome are remarkable milestones not only in the technical evolution of drawing, but as representations of the architectural scene as more broadly defined in this paper. Captured in his sketches were the diverse range of actors and activities that populated the scenes and spaces he represented - scenes in which historical classical memory and new baroque theatricality in public life intersected. These social scenes were recomposed in feverish sketches in verso on large copper plates which then allowed for their mechanical reproduction, consumption, and distribution. Technology combined with an artistic talent for representing a changing society to ensure the production and distribution of a subversive visual message about the transience of power in the new modern princely states of eighteenth-century Europe.

A Piranesi etching of a view from Rome is in fact a hypertext of embedded historical information overlain with a social critique. As analyzed in Digital Modelling for Urban Design, ${ }^{9}$ Piranesi's view of the Arch of Titus is a careful assemblage of the historical artifacts of a site occupied by a range of contemporary social actors - from rag pickers to cardinals. The view thrusts the remains of the triumphal arch to the periphery of the plate and reserves the center of the composition for an informal shack where the marble of the imperial monuments is being pulverized into powder. The angle of the arch reveals the bas-relief of Titus' triumph with the loot from the sack of Jerusalem next to Piranesi's contemporaries looting of forum's ruins.

Piranesi's genius is not only in artistic ability and the employment of technical innovations, but in the critical lens he employs, and the lesson he provides to the purchasers of his scenes. The late eighteenth century was a time of the grand tour of Rome, where lords and princes looked for symbols of power to employ back in the capital cities of northern Europe. At a key historical juncture for the continued influence of antiquity then, Piranesi's Views of Rome embed a critique of power that highlights its ephemeral nature for the future builders of modern Europe. In these images of Piranesi, then, technology combined with an artistic talent for representing a changing society to ensure the production and distribution of a subversive visual message about the transience of power across the new modern princely states of eighteenth-century Europe. Technology and social critique combined.

In these works Piranesi took the new elites of northern Europe through the sheets or layers of Rome's past, but always brought them back to the present moment. In this regard, his works remind us of Henri Bergson, for whom memories are not stored in general in the human brain, but are preserved within specific sheets of the past. ${ }^{10}$ The past occupies regions of memory that must be searched in order for specific events to be recovered. As Piranesi shows us, this applies equally to the city's history, which stores memories through buildings from particular periods within blocks, districts, and neighborhoods. As a lesson, it is applicable anywhere, at any time, and a few short examples are covered in outline here. 


\section{Amps}

\section{1: The Gay Scene}

A walk around Lower Manhattan during the early 1980s presented fragments of an early federal past in town houses and squares. It also presented remnants of an industrial era of crowded tenement houses and large swaths of public housing projects from the era of Robert Moses' slum clearance program in the Lower East Side. These fragments of occupied buildings were interspersed with hundreds of abandoned buildings and vacant lots. On the west side, miles of abandoned piers lined the Hudson River, as well as the hulk of the Miller Highway, closed since its collapse in 1973.

During this time the area became an important locale for the city's gay community. It was however under threat. In 1985 a proposal for the Westway Project, the most expensive highway project ever proposed in the US, was defeated by a coalition of civic and environmental groups. This meant that large areas of lower Manhattan remained open to development and a call for ideas was made for the Hudson River Waterfront by New York's Municipal Art Society. The area was home to 800 -foot warehouses extending into the river which had become playgrounds for men seeking sex with men, but also thrill seekers, exhibitionists, voyeurs, outcasts, artists, poets, and performers. With the developers' "march" up the city from the World Financial Center of Battery Park City temporarily halted, the piers of these empty, silent boardedup remnants of shipping, industry, and trade stood exposed to the elements of tide, wind, rain, and snow.

Safe Sex Piers began as "an anti-proposal for non-development" developed by Brian McGrath in response to call for ideas from the New York Municipal Art Society. It was developed at a time when (1985 to 1995) the impact of AIDS had escalated and the gay scene had become more and more visible. The project thus represented an architectural engagement with perhaps the most important social issue of its day. The pencil on canson drawings of Safe Sex Piers were developed from the first competition boards for subsequent exhibitions through 1990 and became a form of visual/architectural representation that expressly sought to engage in a direct and active social debate (Figure 1).

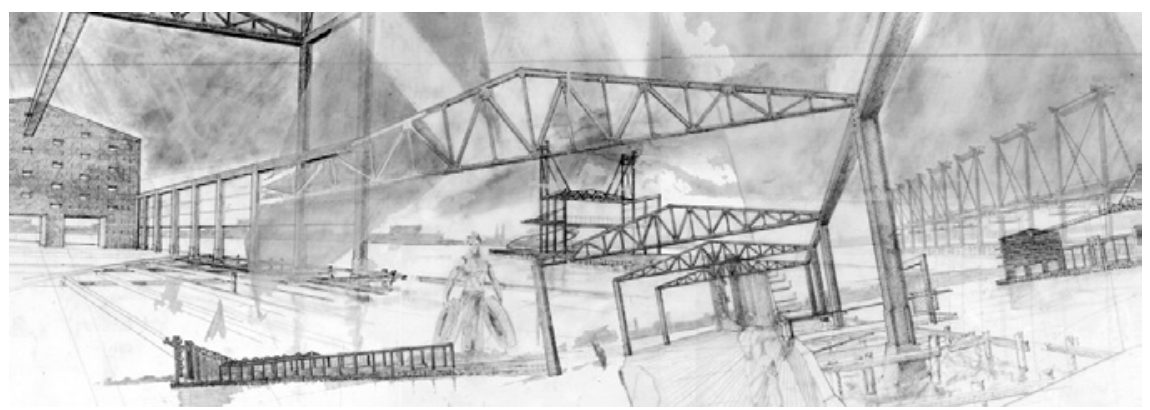

Figure 1. Safe Sex Piers. Brian McGrath 


\section{Amps}

The drawing reproduced here overlays several constructed perspectives that were later used to form a contribution to the exhibition Queer Space at the Storefront for Art and Architecture in Lower Manhattan, 1994.

Not only was this exhibition born out of a mix of social theory, analysis, and various forms of visual representation, it featured an early gallery display of the then new digital modeling software. An elaborate digital model of gay cruising areas in the city was constructed as a continuous landscape - the Rambles in Central Park, the Hudson River Piers, and the 8th Avenue subway line that connects the two. Printed on acetate were serial views created from the virtual camera of the then new 3D modeling software developed by Chris Yesios at Ohio State University, Form $Z$. The display consisted of a giant, curved transparent sheet of Plexiglas, where the voyeurism and exhibitionism that constituted the gay scene of New York could be experienced in a gallery setting through the transparency of the partly digitally created installation.

The project description form states: "There is no Queer Space, Only Different Points of View. It is not about the making of queer space, but it is a representation of the possibilities of individual and minority appropriations of majority space," in other words a queer "scene" rather than queer space. Despite being now twenty years old, the 1994 description of the project resonates with contemporary discourse on the scene as social phenomenon. The queer scene

exists potentially everywhere in the public realm. Unbounded and ever-present, it is the individual's appropriation of the public realm through their personal ever-changing points of view. An acoustical guide and navigational chart are provided in this project to describe a space that can barely be perceived by those outside of it, but vividly present to those who occupy it. The installation aims to invite others to occupy New York City from many different points of view. ${ }^{11}$

Combining drawings and exploring the software by modeling and virtually cruising through New York's various "scenes" the contributions to this exhibition clearly demonstrated how technological advances in representation, image and form creation, did not have to become apolitical and socially devoid of meaning. On the contrary, as was evident from its incipient years, the new technologies feeding contemporary architectural production and imaging could, and should, engage in the panoply of social issues that form our expanded notion of any architecturally contextualized "scene", and which remain as much in need of attention and critique today as they did at any time in history.

\section{1: The Consumption Scene}

Another example of this potential for the technological to become a vehicle for social debate and exploration through architecture, rather than an empty techniques in and of itself, is Siam Central Station in Bangkok and its various 


\section{Amps}

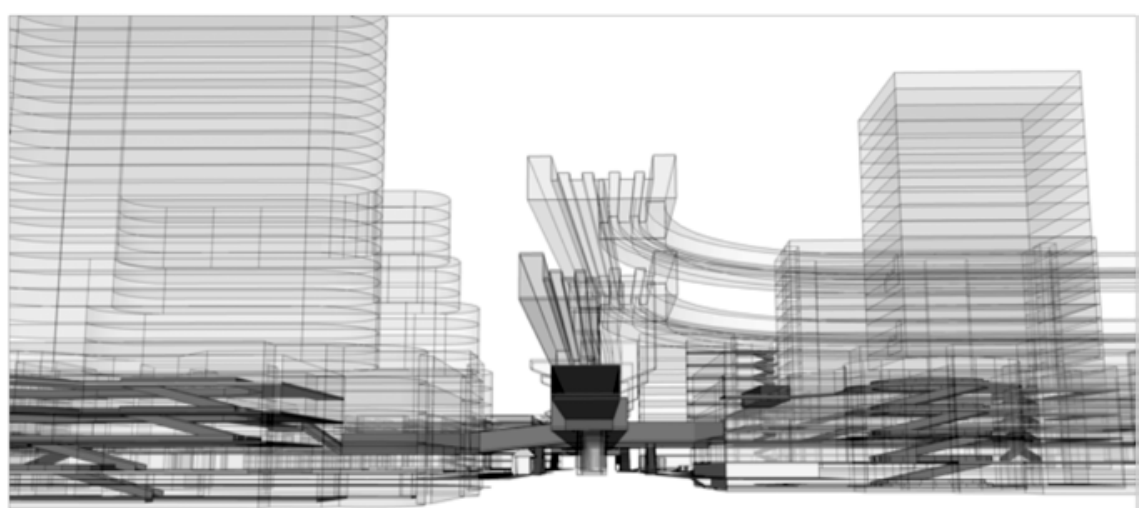

Figure 2. Still from mobile section through Bangkok's Central Shopping District

places of consumption (Figure 2). The technological-architectural context of this project gives a good sense of how the 1990s saw the establishment of the digital in architectural practice and how that was, at least by some, never seen in isolation. In 1991, computer modeling was first introduced by Susana Torre, Chair of the Architecture Department at Parsons School of Design, New York, for the first class of a new graduate program. Form $Z$ was loaded on the new Macintosh personal computers purchased by the department. The course "Analysis and Representation" carried over both semesters and was tied to "Theory of Architectural Form" in the fall semester, and" Theory of Urban Form" in the spring. Digital, hand drawing, and modeling assignments were combined in an experimental approach integrating theory and technology immediately into first year architectural design studios. What was revolutionary was the ability for beginning students to start from 3D modeling in a multi-screen format, and then generate multiple orthographic drawings as cuts through complex three-dimensional forms. Also of interest was a cone of vision that, like a camera, could be situated in the plan and section views of a model to generate endless perspectival scenes.

In 1994, this initiative was repeated by Dean Bernard Tschumi with the introduction of the paperless studio into the curriculum at Columbia University's Graduate School of Architecture, Planning and Preservation. A decade later, all the studios after first year went paperless at GSAPP, including "Advanced Architecture and Urban Design." The first studios included specialized equipment including Silicon Graphics machines and Softimage software - later replaced by PC platforms with 3D Studio Max and Maya. The shift from Form $Z$ was dramatic. Instead of working on a Cartesian w-y-Z plane, architectural projects were developed through animated scene making.

This computerization of architectural education in New York coincided with the globalization of Western higher education, with both the removal of the Iron Curtain in Europe and the rapid growth of Asian economies. It meant that initiatives being developed in places like GSAPP would be 


\section{Amps}

adapted and applied worldwide at ever increasing speeds - especially in emerging economies in boom, the prime example of which at the time was Thailand. Between 1985 and 1995, Thailand was the world's fastest growing economy, with a 10 percent annual growth rate that prefigured the rapid growth of China, which soon surpassed it. However, in 1997 a devastating burst of the growth bubble and an economic crisis spread across East Asia. Both that period and its aftermath represented major economic, political, and social transformations in the country which are still playing out on the streets and in the corridors of power today.

It was in this context that, towards the end of this recession, a new global consumer economy was emerging. Definable as a veritable "shopping scene" this consumerist culture pulled the Thai economy out of recession on the back of middle-class consumption, tourism, and leisure industries and by 1999 it had its most obvious architectural manifestation - the ostensible shopping mall that is Siam Central Station. Opened upon the completion of the two overhead lines of Bangkok's mass transit system its primary transit intersection, Siam Central Station, is a mixed use space that celebrates more than anywhere else in Thailand the new consumer culture. However, its construction also coincided with the development of a range of digital architectural representational tools.

During the boom years, Chulalongkorn University Faculty of Architecture had invested in new digital technology and began the integration of computer technology into the architecture curriculum. It also helped teach digital modeling in the new graduate urban design program. However, its key development was the construction of a collective digital model of the "CSD" of Bangkok - the central shopping district that, in the absence of a more typical central business district, or CBD, emerged over the decade 1995-2005 and is centered around Siam Central Station. The digital model was constructed in easy to use sketch-up software to cut a "mobile" or "moving section" through this urban district. The aim of mobile or moving section was not simply to examine the formal qualities of the architecture in question, but to examine the multiplicity of the global urban scene evident in the project. An animated cross-sectional perspective, it permitted the simultaneous examination of a new kind of multilevel public space and its social production by, and of, a new mass public.

By modeling layered architectural "scenes" in "moving" drawings, it was possible to not only visualize the space of representation - the glittering surfaces of the global city - but also how that urban space was being appropriated, adapted, and reformed. This was achieved through layered time lines, color-coding of degrees of publicity and privacy, and the application of the "mobile section" technique. Much like a wall section reveals the constructional aspects of a building, the "mobile urban cut" revealed how the global staging of the urban spectacle was being constructed, perceived, and imagined as an architectural or urban scene in which modern living could be analyzed and dissected.

The expanded architectural scene visible through this technology operates 


\section{Amps}

in social, cultural, political, artistic, and scientific contexts. It contains the material reality of the physical setting, as well as the potential to analyze demographic, economic, or environmental information. The "mobile cut through the architectural scene" is then, a meta-modeling technique that transcends single disciplinary lenses and moves us clearly from the realm of visual architectural representation into the more complex and expanded realm of "scene" as discussed in this paper. It thus corresponds to Alan Blum's argument that there is a grammar to any social phenomenon we define as a "scene" which is rule based, and therefore marked by regularity, extensiveness, mortality, collectivization, theatricality, transgression, and spectacle. ${ }^{12}$ Architectural drawing should aim to capture this. New modelling techniques can, and as indicated here do, help to do this.

\section{1: The Crime Scene}

An example that clearly warns us of the potential pitfalls of combining the technological with the social in architectural discourse and critique is the "crime scene" demarcated in Lower Manhattan following the terrorist's attacks on the World Trade Center in September 2001. From May 2002 to January 2003, the Lower Manhattan Cultural Council hosted an artist's residency and installation at the World Financial Center, closed since the collapse of the adjacent World Trade Center. For the residency, an animation was developed in which the physical history of Lower Manhattan - geological, environmental, ecological, and built - could be experienced in visual relation to the actual clearing of Ground Zero and the ensuing planning discussions. New York Here and Now imagined new ways of accessing information in public space, emphasizing the viewer's body in motion within a physical architectural scene and its representation (Figure 3).

The project was a development of the project Manhattan Timeformations, a website for and installation in the Skyscraper Museum of New York City. ${ }^{13}$ The interactive website displayed drawings from a densely layered model, giving the viewer an interface that approximates the software used to generate the model. The information appeared orthographically in plan as a temporal sequence mimicking the construction of Manhattan over 300 years. At that point in the sequence, an animation tipped the model to a frontal elevation to display the z-axis, in which a 3D model of all the high-rise office buildings in the Wall Street and Midtown business districts were placed on a vertical time line. In between plan and elevation, an animation revealed numerous axonometric projections between a one and eighty-nine degree frontal projection.

In the years following the destruction of the World Trade Center on September 11, 2001, the interactive website of Manhattan Timeformations became a memorial as well as an archive of New York at the end of the twentieth century. Reaching a vast unseen audience via the internet it gives an indication of the larger global impact of architecture made possible by digital design. In this context of "intense trauma and fervent rebuilding," Lower 


\section{Amps}

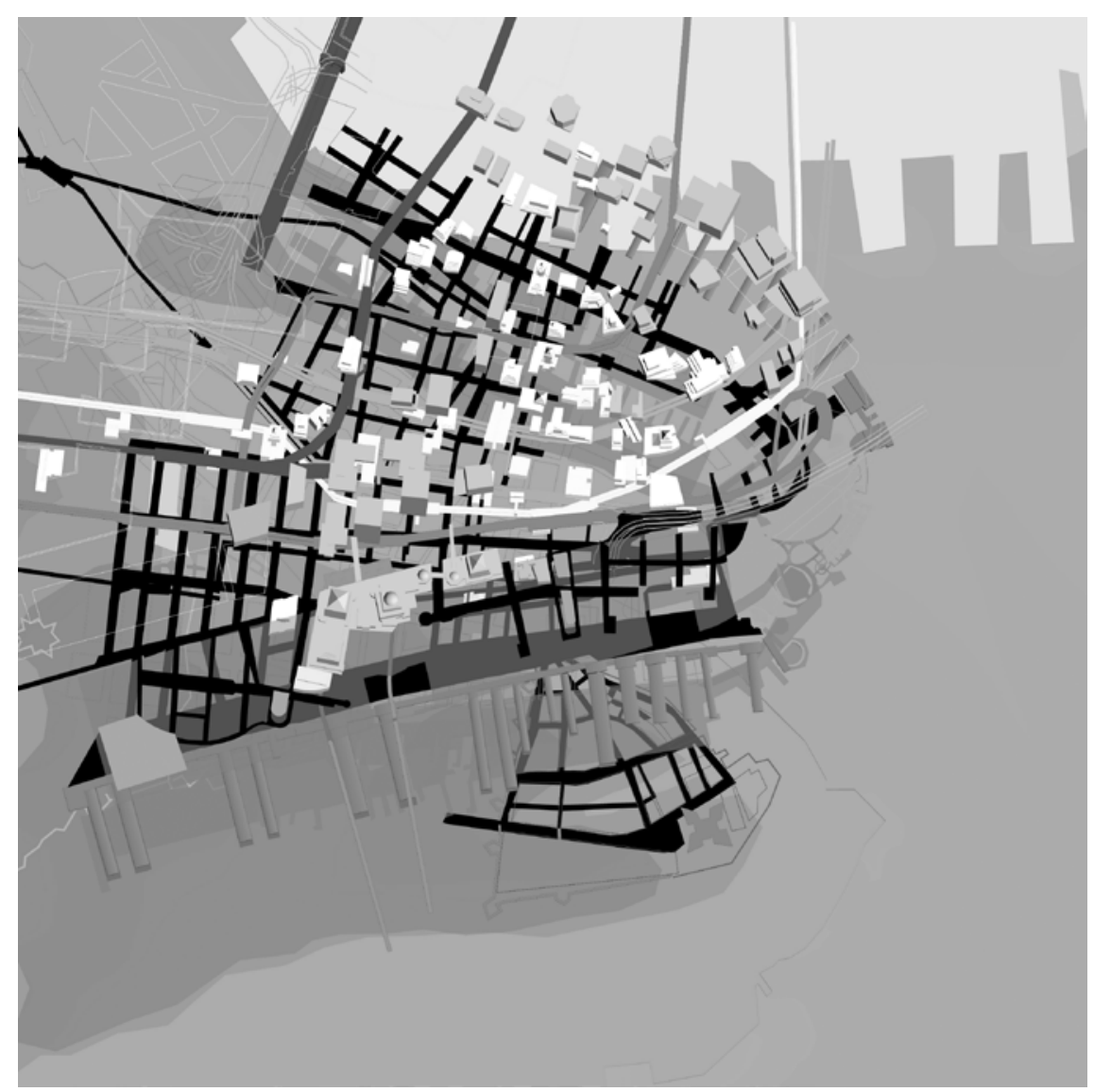

Figure 3. Still from New York Here and Now

Manhattan Cultural Council and the World Financial Center hosted artist residencies for site-specific installations for tourists, visitors, and corporate tenants. It was located in the Winter Garden in 2002. The call was to create works of art for a population returning to a site of trauma.

In one of the exhibition catalogue's essays, "Siting the Everyday," Nuit Banai describes how New York Here and Now "imagines new ways of accessing information by destabilizing current methods of knowledge organization." It "combines architectural mapping techniques and structuralist-inspired film practices to produce a hybrid computer model that [the artist/constructor] calls a "moving picture.." 14 In the installation, the images resulting from Manhattan Timeformations were displayed so as to emphasize the viewer's body as equally important for the production of knowledge as the shifting constellation of external factors. The placement of this moving picture in the Winter Garden beside a large window built to view the reconstruction process 


\section{Amps}

of Ground Zero, further underscored the way in which viewing is an activity constituted by the interaction of various regimes: cartography, architecture and urban planning, with the carnal density of the body in motion."15

In addition to these positive examples of how technologically laden architectural representations can create alternative "scenes" of debate manifest in the 2002 Winter Garden exhibit, the World Trade Center site also gave us other cases of interest. These included Beyer, Blinder and Bell's banal renderings of Lower Manhattan Development Corporation's (LMDC) preliminary design concepts which represent the worst sort of influence new digital powers of presentation can have on architectural critique and understanding - reducing it to a glossy image. However, other potentials of digital tools were also explored and a huge global urban design constituency was formed that began to comment on the future of Ground Zero and New York from very early on. Indeed, even the official design process encouraged this, with computer models and animations combined with interactive displays, websites, public exhibitions, opinion polls, surveys, and meetings.

All this constituted a new form of public discourse emerging out of the ashes of Ground Zero which, momentarily, disrupted normative architectural knowledge and practice. One example of the public engagement through new digital forms and formats initiated around this project was the interactive "Listening to the City" event facilitated by AmericaSpeaks, and culminating in the mass media spectacle of the Innovative Design Study where LMDC commissioned seven teams to display proposals in the Winter Garden of the shopping mall at Battery Park City. Again, the potential for new technology to take our engagement with a given "architectural scene" into much more socially innovative and beneficial areas is obvious.

\section{Pedagogical Scenes}

Other examples of how to apply the powers of new digital tools in architecture for social critique around architectural projects are found in various pedagogical initiatives the authors have engaged with in Taiwan, China, and Hong Kong. Tainan, Shanghai, and Hong Kong are three cities that have over the past few years served as sites of investigation for student projects. Beginning as filming and modeling exercises these projects have evolved more recently into complex interactive performances in schools, design fairs, galleries, and public spaces. In each case, digital technology is not only used as a new technology of visualization, but as a tool to shift thinking from the "linear and objective" to the "circuit and the relational" - from only considering parts, to regarding the whole. The premise of this approach is that it is imperative to explore digital media as a new architectural imaging system for thinking about architecture and cities as places of relationships responsive to current understandings of the nature of society and the world.

In 2008 this approach was brought to the fore in Haunting the Big Dig - a design-research project that examined the abandoned proposal for an 


\section{Amps}

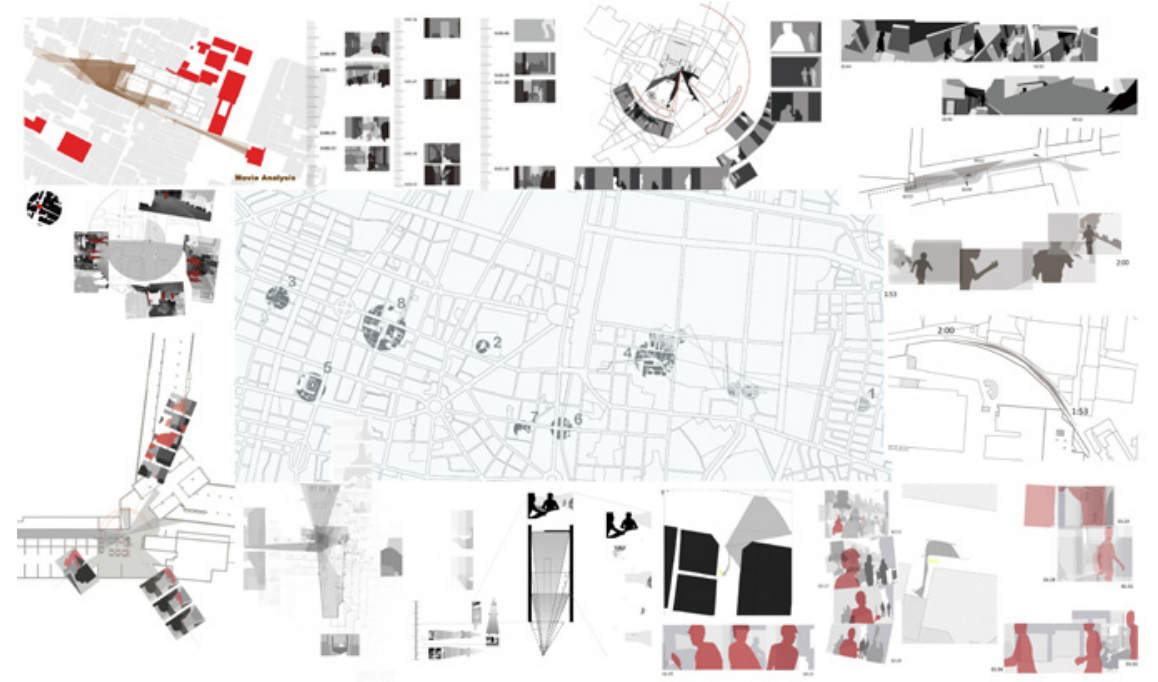

Figure 4. Student work from NCKU Cinemetrics Workshop, 2014

underground shopping mall along Hai-an Road in Tainan. As this would have been an urban intervention in the most historical part of the city, the workshop examined new ways of integrating an emerging creative and leisure scene into the older patterns of life in the area. In 2011, the project Measuring the Sensori-Motor City was exhibited at Taipei Design Week and Parsons Gallery New York and was premised on extending design projects from images into the sphere of performance. The modus operandi of Measuring the Sensori-Motor City asked the students to spatially represent one of three the short film scenes from Yasujiro Ozu, Jean Luc Godard and John Cassavetes', ${ }^{16}$ in such a way as to explore cultural differences. ${ }^{17}$

In the most recent of these workshops in 2014, 8 New Scenes of Tainain, Cheng-Luen's research on the origin of Chinese drawing has been integrated with "cinemetric" techniques developed by McGrath which break down movement into perception, affection, impulse, action images, and time into reflection and relation images. Described as a sensory motor system cinemetrics involves everyday scenes being filmed, digitally manipulated, and studied frame by frame. Adapting cinemetric techniques, developed in the West, and premised on the theory of technological representation, students applied non-Western concepts in an attempt to move thinking away from the objectfocused approach induced by contemporary digital modes of representation, towards more intangible issues of affection through the filter of Ye XiaoYan's folio of ten ink wash drawings (1000 AD).

Ye Xiao-Yan's Ten Scenes of West Lake provide ways of understanding the representation of a scene as an "attentive circuit" of specific sensations that come with specific local landscapes, seasons, and times of day. They provide 


\section{Amps}

an example of a form of architectural representation functioning as a form of environmental monitoring in a cultural rather than scientific way ${ }^{18}$ and capture David Hockney's suggestion that "Chinese painting is an art of time as well as of space ... [in which] ... everything is perceived sequentially. There is no way you can take everything in at the same time." ${ }^{19}$ Applying this combinatory approach of Chinese landscape scenic tradition and the cinemetric techniques of McGrath, these recent workshops captured and reassembled the embodied everyday routines within the contemporary and post-colonial cultures of Tainan, Shanghai, and Hong Kong to explore sensory motor relationships between the body and urban contexts. ${ }^{20}$ Combining performance, digital media, modeling, and drawing to recover the attentive circuits established in Chinese landscape scene tradition in contemporary society, they are just one more example of ways in which contemporary digital potential can be used to take architectural thinking into "scenes" far more expansive and challenging than mere photo-realistic representation or, indeed, spectacular, but empty, parametric forms.

\section{Conclusion}

Through its sequential description of design, student and professional projects over a period of more than thirty years this paper has attempted to do two principal things. First, it has given an indication of how, over that period, digital technologies have increasingly invaded the practice and production of architectural design, education, representation, and debate. Secondly, it has attempted to indicate how this process, which often is seen as an end in and of itself is, can and should be seen as secondary to the social context in which architecture exists, the political issues it is forced to engage with, the cultures it needs to understand, and the social critique it can always offer.

Using the semantic and theoretical vehicle of the "scene" to frame this argument, the paper has suggested the "scene" is something bigger and far more complex than architectural scenery - the glossy architectural forms presented in public or the spectacular buildings of digital design which typical mediate and dominate public engagement with architectural discourse. To do this, it began by laying out a historical precedent through the work of Piranesi and then returned to the gay scene of 1980s New York to give a sense of how, in its very incipient years, the digital turn was already being appropriated by more socially minded designers and thinkers. Moving forward ten years it considered the example of Bangkok's primary transit intersection and commercial center, Siam Central Station, as a very real project which was socially analyzed, and not just commercially presented, through the new technologies then available to architectural practice.

While this example was a clearly commercial example of the wider "scenic" understanding available to and through technology, the following case of the World Trade Center project in the early 2000s gave us an opportunity to speculate on new technologies of representation can be used against the 


\section{Amps}

simplifying and spectacularizing tendencies of mass media and realistic rendering - both from a design and citizen participatory angle. In the final "pedagogical" example, we moved away from the argument about the digital turn somewhat, to focus on another aspect of our understanding of the "scene" - the fact that almost any social context today is inherently multicultural and can therefore draw on multifarious representative traditions which, when overlaid with the possibilities opened up by alternative uses of Western established forms of digital representation, move our social understanding as architects onto newer and richer terrain. In short, we have suggested that focusing on digital advances in architectural representation as ends in themselves limits our understanding of architecture as a primarily social phenomenon and, in addition, limits the scope of the technologies in question.

\section{Notes}

1 Jean Baudrillard, Simulacra and Simulation, trans. Sheila Faria Glaser (Ann Arbor, MI: University of Michigan Press, 1994).

2 Brian McGrath, Digital Modelling for Urban Design (London: Wiley, 2008)

3 Daniel Silver, Terry Nichols Clark, and Clemente Jesus Navarro Yanez, "Scenes: Social Context in an Age of Contingency," Social Forces 88.5 (2010): 2293-2324.

4 In particular the authors would like to acknowledge Victoria Marshall, Jose DeJesus, Mark Watkins, and Jean Gardner

5 Oxford English Dictionary (Oxford: Oxford University Press, 2002).

6 Robin Evans, The Projective Cast (Cambridge, MA: MIT Press, 1995).

7 Marguerite Yourcenar, The Dark Brain of Piranesi and Other Essays (New York: Farrar, Straus and Giraux, 1984).

8 Jonathan Scott, Piranesi (London: Academy Editions, 1975).

9 Brian McGrath, Digital Modelling for Urban Design (London: Wiley, 2008).

10 Henri Bergson, Matter and Memory, trans. Nancy Margaret Paul and W. Scott Palmer (New York: ZONE Books, 1991).

11 Brian McGrath, "There is No Queer Space," Queer Space (New York: Storefront for Art and Architecture, 1994).

12 Alan Blum, "Scenes," Public 22/23 (Fall 2001): 10.

13 http://www.skyscraper.org/timeformations/intro.html.

14 Nuit Banai. "Siting the Everyday," in New Views: World Financial Center, ed. Erin Shirreff. New York: Lower Manhattan Cultural Council, 2003.

15 Banai. "Siting the Everyday."

16 The "scenes" examined were the small traditional home in Ozu's Tokyo, where living, dining, and sleeping occur in one space; the modern flat in Godard's Rome, where the panning camera loses track of the occupants in the spacious apartment; and Cassavetes' Los Angeles, where the car and large single-family house provides a cavernous multi-level landscape for the domestic scene.

17 Brian McGrath, "Measuring the Sensori-motor City," in In situ-de visu-in motu: Architecture, cinéma et arts technologiques, ed. Irena Latek et al. (En Crausaz: Infolio, 2014). 


\section{Amps}

18 Brian McGrath, "Silicon Valley in Paradise: Wiring Hangzhou's Waterbody," Growing Cities in a Shrinking World: Urbanization in India and China (Delhi: Macmillan, 2010).

19 David Hockney, Photographs by David Hockney, traveling exhibition catalogue (New York: International Exhibits Foundation, 1986).

20 Cheng-Leun Hsueh, "From the Origin of Drawing to Cinemetrics," Nakhara 7, History in Design: Writing Asian Modernity (October 2011): 127-38; Brian McGrath et al., "Club Cinemetrics: New Post-Perspectival Design Methodologies," $A D 17.1$ (January/February 2009).

\section{Bibliography}

Banai, Nuit. "Siting the Everyday." In New Views: World Financial Center. edited by Erin Shirreff. New York: Lower Manhattan Cultural Council, 2003, 6-11.

Baudrillard, Jean. Simulacra and Simulation. Translated by Sheila Faria Glaser. Ann Arbor, MI: University of Michigan Press, 1994.

Bergson, Henri. Matter and Memory. Translated by Nancy Margaret Paul and W. Scott Palmer. New York: ZONE Books, 1991.

Blum, Alan. "Scenes." Public 22/23 (Fall 2001): 7-35.

Cheng-Leun Hsueh. "From the Origin of Drawing to Cinemetrics", Nakhara, 7, History in Design: Writing Asian Modernity (October 2011): 127-38.

Evans, Robin. The Projective Cast. Cambridge, MA: MIT Press, 1995.

Hai Ren. "Aesthetic Scenes: A Critique of the Creative Economy in Urban China." Conference paper New Urban Forms, New Fields of Inquiry: China and India, The New School, April 17-18, 2015. March 12 version provided by author.

Hockney, David. Photographs by David Hockney. Traveling exhibition catalogue. New York: International Exhibits Foundation, 1986.

McGrath, Brian. "There is No Queer Space." Queer Space. New York: Storefront for Art and Architecture, 1994.

McGrath, Brian. Digital Modelling for Urban Design. London: Wiley, 2008.

McGrath, Brian. "Silicon Valley in Paradise: Wiring Hangzhou's Waterbody." Growing Cities in a Shrinking World: Urbanization in India and China. Delhi: Macmillan, 2010, 106-17.

McGrath, Brian. "Measuring the Sensori-Motor City." In In situ-de visu-in motu: Architecture, cinéma et arts technologiques, ed. Irena Latek, Clotilde Simond, Françoise Very, and Sophie Paviol. En Crausaz: Infolio, 2014, 30-45.

McGrath, Brian, Cheng-Leun Hsueh, Paul Chu Hoi Shan, Jose DeJesus, and Victoria Marshall. "Club Cinemetrics: New Post-Perspectival Design Methodologies.” $A D$ 17.1 (January/February 2009).

Shane, David Grahame. "Balkanization in the Post-Modern City." In The Mortal City, edited by Peter Lang. New York: Princeton Architectural Press, 1995.

Silver, Daniel, Terry Nichols Clark, and Clemente Jesus Navarro Yanez. "Scenes: Social Context in an Age of Contingency." Social Forces 88.5 (2010): 2293-2324.

Yourcenar, Marguerite. The Dark Brain of Piranesi and Other Essays. New York: Farrar, Straus and Giraux, 1984. 